\title{
Carbon Emissions Intensity Research in Guangdong Province Based on Input-Output Method
}

\author{
Chen YU ${ }^{1}$, Takeshi MIZUROYA ${ }^{1}$, Yoshiro HIGANO ${ }^{1}$, Yucheng $\mathrm{ZHU}^{2}$ \\ ${ }^{1}$ Graduate School of Life and Environmental Sciences, University of Tsukuba, 1-1-1 Tennodai, Tsukuba, \\ Ibaraki, 3058572, Japan \\ ${ }^{2}$ Jiaxing University, No. 56, South Yuexiu RD, Jiaxing, Zhejiang, 314001, China \\ *Corresponding Author: Chen YU, Graduate School of Life and Environmental Sciences, University of \\ Tsukuba, 1-1-1 Tennodai, Tsukuba, Ibaraki, 3058572, Japan

\begin{abstract}
Guangdong province as the pioneer of the national economy in China, occupies an important position, hence, study of carbon emission of Guangdong province, is of great significance. To study carbon emission condition in Guangdong province from the perspective of the whole national economy requires use of input-output analysis method. By use of input-output table in 2007 in Guangdong province, and measurement of direct carbon emission intensity and full carbon emission intensity in different sectors in 2007 in Guangdong province, this article divides the 27 industries of Guangdong province into three types, and makes a conclusion of carbon emission characteristics of different industrial sectors. According to the characters of their carbon emissions, we can put forward different mitigation measures.
\end{abstract}

Keywords: input and output; Carbon emissions; Guangdong province,

\section{INTRODUCTION}

At present, climate warming has become a serious problem of the globe. Greenhouse gas emissions are the main reasons for the warming of the climate. In order to improve the serious situation of climate warming and the status quo, change high energy consumption and high pollution development method; reduce greenhouse gas emissions and develop a low-carbon emission production method, more and more governments start to shift from the current high energy consumption and high pollution development mode, and highly promote economic and industrial structure adjustment, optimization of energy structure, improvement of energy efficiency, etc.

Guangdong province, as the pioneer of China's national economy, occupies a very important status in the national economy. Study of carbon emission in Guangdong province, is hence of great significance. To find a way in emission reduction, must conduct from the perspective of the national economy. Judging only from the energy consumption situation of one industry to determine whether it is an energy-intensive sector or high carbon emission department, will ignore the technical and economic ties between sectors and energy consumption and carbon emissions implied in intermediate inputs, hence results in a failure to reach overall emission reduction. To study carbon emission in Guangdong province from the perspective of the whole national economy requires the use of inputoutput analysis method.

Input-output method is comprehensively studying the quantitative relation between various specific industries from the perspective of national economy as a whole. By input-output table and model, it can clearly reveal the inner link between each industry of national economy, especially to reflect the direct and indirect contact between various departments, industries during production process in the national economy. 
This article utilizes input-output table in 2007 in Guangdong province. Through input-output model to Calculate direct carbon emission intensity and full carbon emission intensity in different industries, and sum up carbon emissions characteristics of different types industrial sectors, and put forward different according to different sectors of mitigation measures.

\section{REVIEW OF RELATED LITERATURE}

At present, domestic and foreign scholars and carbon intensity factors research, as shown in the following review.

\subsection{Research on carbon emissions intensity}

Machado, et al (2001), through measurement of the carbon emission in the Brazil international trade, pointed out that indirect carbon emission of all non energy export goods (mainly manufacturing goods) is very high in 1995 .

G Ipek Tunc (2007) made a research on carbon emission as well as related reduction responsibility of all industries in turkey using the input-output model, finding that the manufacturing sector takes the first place on carbon dioxide emission, assuming the important obligation to reduce emission.

David Andres (2011) think that the biomass fuel, hydrogen power tools are the key to the next 50 years the United States to reduce the carbon intensity of transportation, natural gas and nuclear energy can reduce transportation carbon emissions intensity by $20 \%$ to $50 \%$, looking for stable and sustainable clean energy to replace fossil energy still is the difficulty of future research.

Yue (2010) used The Chinese provinces Theil coefficient is a measure carbon intensity difference, Theil coefficient biggest advantage is having carried out the nature of decomposition between different regions, the regional carbon emissions and drawn the sort of per capita emissions are: Eastern> Central> Western But carbon intensity is much higher than the eastern Midwest region, which features high energy-consuming industries and central and western regions accounted for a higher proportion of industry closely.

Zhao et al. (2011) used the Theil index analyze spatial differences in the level of Chinese provincial and regional carbon intensity, further analysis of spatial autocorrelation model regional carbon emission intensity and spatial evolution characteristics of dependency through space. Studies have shown that the carbon intensity of the eight economic regions presented three differentiation trend of intraregional similar level of carbon emission intensity, carbon intensity differentiation between regions is the main reason for the expansion of the overall difference. Spatial differences carbon intensity is closely related to regional resource endowments, economic development, industrial structure and energy efficiency and other factors.

$\mathrm{Li}$ and Zhou (2012) used he thought of gray relational degree, investigate the problem of carbon emissions from the industrial structure strength point of view, are the main factors come second industrial area of carbon emission intensity, and to explore the future of the industrial structure adjustment of China's carbon reduction row strategy to effectively control the impact of industrial development on the emission intensity of carbon.

Cheng et al. (2013) used method of the United Nations Intergovernmental Panel on Climate Change (IPCC) provided on paper estimates the country's 30 provinces 1997--2010 carbon intensity, spatial autocorrelation analysis and spatial econometric models panel discussed Temporal and spatial patterns Chinese provincial scale carbon intensity. Studies have shown that the carbon intensity of China's energy consumption has a significant spatial clustering feature on the provinces scale and agglomeration degree has growing trend, while carbon intensity high value and low concentration areas gathering area showed a certain degree of path dependence or space locked.

\subsection{Research on factors affecting the carbon emissions intensity}

Ang, etc., Liu and other methods to compare the evolution of IDA study; Ang (2000) considered LMDI decomposition model is superior to other indices overall decomposition model, Ang (2005) and other methods using different IDA 1985-1990 China Industry carbon emissions resolve that industrial 
output and energy intensity of carbon emissions growth respectively from the positive and negative effects.

Greening et al. (1998) method using AWD earlier on carbon emissions intensity from 1971 to 1991 the production sector in OECD countries decomposed that its decline in energy intensity and energy prices have a major impact.

Bhatta-charyya et al. (2010) found that the use of research methods LMDI, 1990-2007 EU-15 emissions intensity decreased mainly from Germany and the UK, which is the decisive factor in energy intensity decreased.

Fan and Tsai HT (2007) method using AWD material production sectors of Chinese carbon intensity from 1980 to 2003 were analyzed, that the carbon emission intensity decreased mainly due to reduction in energy intensity and primary energy structure changes.

Stern et al. (2010) use stochastic frontier model to analyze energy intensity factor input - output ratio, temperature and technological progress in energy intensity and carbon intensity of China and India, scenario forecast that China should achieve carbon emission intensity decreased goals requires more effort than India, and to adopt a more aggressive emission reduction policies.

Obas John Ebohon et al. (2006) in sub-Saharan Africa for the study, the carbon intensity of industrial and non-oil-producing oil industry to compare different subintervals empirical analysis of different factors, that the energy intensity energy structure and economic growth are the main factors of carbon emission intensity change.

KM Christie et al. (2011) for agricultural carbon intensity Australia Tasmania analyzed that science and technology and arable farming livestock manure structure can affect changes in agricultural carbon intensity.

Simone Gingrich et al. (2011) for Austria, Czech and Slovakia in 1830 - 2000 were analyzed carbon intensity data, and comparative analysis of the number of Carbon emissions in both countries by Kaya Identities intensity factors, and that the energy intensity of industrial structure changes in carbon intensity has an important role.

Wang and Huang (2008) Factors affecting Jiangsu Province carbon intensity analysis from both horizontal and vertical by factor decomposition model. Studies have shown that changes in carbon intensity joint action by the industry in Jiangsu Province, carbon intensity and industry output share. With respect to the share of industry output, industry emissions intensity greater impact on the overall carbon intensity of social change. While the industrial sector on the whole society contribution to the larger carbon intensity, internal structural changes in the industrial sector have a greater impact on carbon emissions intensity change.

Yue (2010) using stepwise linear regression method, respectively, and the carbon intensity of 19951999,2000-2004 period 2005-2007 these three factors were analyzed. Study concluded that in addition to the structure of the industrial sector has a significant impact on the carbon intensity of external energy resource endowment is one of the determinants of carbon emission intensity.

Zhu and Zhang (2011) using the logarithmic mean of Di's decomposition (LMDI) method 1995-2008 Shanghai carbon intensity decomposition analysis, analyzes the influencing factors in Shanghai carbon intensity. The results showed that the industrial sector decreased energy intensity is the main reason for decline in energy intensity in Shanghai Shanghai carbon emissions intensity decline comes mainly from secondary industry, but because of the traditional industrial energy saving potential is limited, in recent years, industrial energy intensity decreased speed slowing, its contribution to the reduction of carbon intensity tends to decrease.

Liu et al. (2014) applied to the average weighted number of decomposition (LMDI), based in Xiamen City in 2005-2010 all departments terminal consumption data on carbon emissions intensity index factor decomposition, the carbon intensity of research trends and its influencing factors, The results show that, from the perspective of the impact effect, economic efficiency on carbon emissions intensity decreased largest contribution, a minimum contribution of carbon emissions reduction coefficient; reduction contribution from the sector perspective, the second largest industry 
contribution, the contribution of household consumption to a minimum.

Zhang et al. (2014) is based on analysis of DEA estimates the technological progress situation in China 30 provinces, municipalities, 1990-2011 years, then use the panel data model estimation methods, divided the country as a whole, sub-regional, phased, integrated multi- Empirical tests of the impact of technological progress on carbon emissions intensity. The results show that technological progress is an effective means to reduce carbon intensity, foreign investment in carbon intensity has a significant negative effect on the impact of technological progress on carbon emissions intensity has obvious regional differences, technological progress and carbon dioxide emissions REGIONS Strength significant negative correlation, the central region is a significant positive correlation.

\subsection{Conclusion}

In the study of carbon intensity, scholars tend to study space and space difference in carbon intensity.

Research on the carbon intensity factors, the existing literature can be divided into two categories. One is to use factors Analytical method for carbon-intensive structural decomposition analysis (SDA) and the index decomposition analysis (IDA); the other is the use of econometric models for empirical testing.

Study of global carbon emissions intensity also more and more refined, economies of scale factors, energy intensity, energy mix and the industrial structure is increasingly used to study carbon intensity; the carbon emission intensity by the research process to Look, energy and industry is still a focus of the study, the energy structure, energy efficiency and industrial structure play a very important role in carbon intensity.

However, the input-output thinking into question the strength of carbon emissions come from the perspective of the entire national economy to study carbon intensity, is still not very common widely.

Therefore, this article draws on previous valuable experience from the perspective of the entire national economy to study the emissions situation in Guangdong Province, which requires the help of input-output analysis. In this paper, Guangdong Province in 2007 input-output table, input-output model estimates through direct carbon emission intensity and carbon intensity entirely Guangdong Province different industrial sectors in 2007, the Guangdong Province 27 industrial sectors became divided in three industries, induction the characteristics of different types of carbon emission sectors, and according to their carbon emissions characteristics of different emission reduction measures proposed for different industrial sectors.

\section{MODEL AND STATISTICS}

\subsection{Data processing}

This article selects the input-output table of 42 industries in Guangdong province in 2007; division energy consumption, energy balance sheet, terminal energy consumption statistics of Industry from 2008 statistical yearbook, as well as data from China's energy statistics yearbook 2008.

This paper adopts all kinds of carbon emission coefficients provided by Institute of Energy Research of National Development and Reform Commission as a basis for calculation, as shown in table 1:

Table 1. Carbon emissions coefficient of all kinds energy consumption

( Unit: tons of carbon/tons of standard coal )

\begin{tabular}{|c|c|}
\hline Kinds of energy & Carbon emission coefficient \\
\hline Coal & 0.68 \\
\hline Coke & 0.77 \\
\hline Natural gas & 0.52 \\
\hline Crude oil & 0.66 \\
\hline Gasoline & 0.62 \\
\hline Kerosene & 0.62 \\
\hline Diesel engine & 0.66 \\
\hline Fuel oil & 0.72 \\
\hline Electric power & 1.81 \\
\hline
\end{tabular}

Data source : "IPCC guidelines for national greenhouse gas inventories in 2006" 


\subsection{Industry Processing}

Because the industry classification in input-output table is different from classification in national economy. In order to link up the input-output table and energy statistics, and ensure consistency of research, merger and adjustment of industries should be executed firstly. On the basis of input-output table of 42 industries in 2007 and divisions total energy consumption table from Guangdong statistical yearbook in 2007, and consideration of "national economy industry classification and code", the industry classification basis is adjusted in a line with each other, and finally set up input-output table for the 27 industries, as shown in table 2

Table 2. Input-output tables of 27 industries

\begin{tabular}{|c|c|}
\hline Serial number & Industries \\
\hline 1 & Agriculture \\
\hline 2 & Coal Mining and Dressing \\
\hline 3 & Oil and gas industry \\
\hline 4 & Other mining and separating industry \\
\hline 5 & Food manufacturing and tobacco processing industry \\
\hline 6 & Textile industry and related industries \\
\hline 7 & Wood processing and furniture manufacturing \\
\hline 8 & Paper printing and stationery and sporting goods manufacturing industry \\
\hline 9 & Oil processing and coking and nuclear fuel processing industry \\
\hline 10 & Chemical industry \\
\hline 11 & Non-metallic mineral products \\
\hline 12 & Metal smelting and rolling processing industry \\
\hline 13 & Fabricated metal products \\
\hline 14 & General and special equipment manufacturing \\
\hline 15 & Transportation equipment manufacturing industry \\
\hline 16 & Electrical machinery and equipment manufacturing \\
\hline 17 & Communication equipment, computers and other electronic equipment manufacturing \\
\hline 18 & Instrumentation and cultural office machinery manufacturing \\
\hline 19 & Arts and crafts, and other manufacturing industries \\
\hline 20 & Scrap waste \\
\hline 21 & Electricity, heat production and supply industry \\
\hline 22 & Gas production and supply industry \\
\hline 23 & Water production and supply industry \\
\hline 24 & Construction industry \\
\hline 25 & Transportation, warehousing and postal service \\
\hline 26 & Wholesale and retail trade catering industry \\
\hline 27 & Other services \\
\hline
\end{tabular}

\subsection{Research methods}

From the perspective of input-output analysis, not only research on direct carbon emissions, but also analysis on carbon emissions can be conducted. Thus using input-output method can estimate the direct carbon emission intensity, full carbon emission intensity, and other indexes of each industrial sector. 
Basic input-output model is as follows :

$$
X=Y(I-A)^{-1}
$$

Among them, $X=\left(X_{1}, X_{2}, \ldots, X_{n}\right)^{T}$ is total output column vector, $X_{i}$ representing output of $\mathrm{I}$ industry; $Y=\left(X_{1}, X_{2}, \ldots, X_{n}\right)^{T}$ is the final demand column vector, $Y_{i}$ representing final demand of $\mathrm{I}$ industry. A represents the direct consumption coefficient matrix, element $a_{i j}$ representsdirect consumption on I product for per unit output of $\mathrm{J}$ industry product. $L=(I-A)^{-1}$ full demand coefficient matrix, also known as leontief inverse matrix, representing when $\mathrm{J}$ product increase a unit final demand, its full demand for the product I.

To process the energy consumption structure in Guangdong province, this article selects regional numbers from China's energy statistical yearbook in 2008, and gets the energy consumption structure of Guangdong province through calculation, as shown in figure 1.

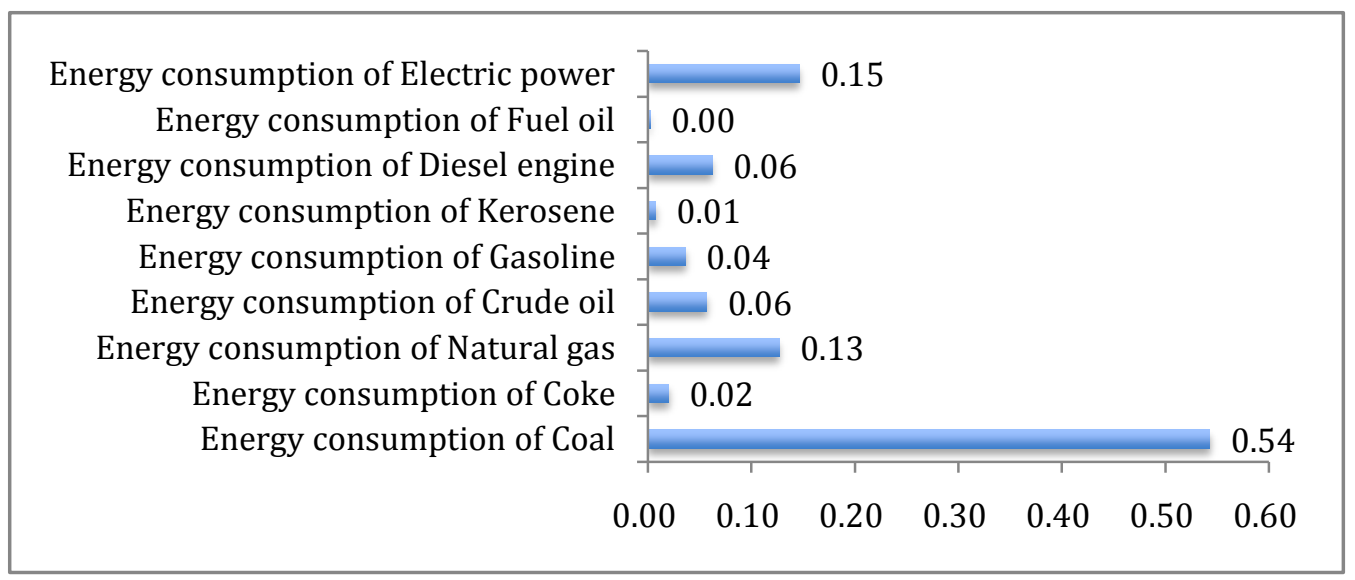

Figure1. Energy consumption structure in Guangdong province in 2007

Based on"2006 IPCC national greenhouse gas inventory guidelines"recommended method, information about the activity degree of human beings (EC) with emission coefficient and clear coefficient which quantifies unit activities (EF) are combined to get the following formula:

$$
E=\sum_{i j} E C_{i j} \times F E_{i}
$$

Among them, E represents carbon emission quântity;J represents energy type; I represent industries or economy sector; EC represents consumption standard of I industry for J energy type; EF represents carbon emission coefficiency of all kinds energy consumption.

According to related energy consumption data of each industry, the direct carbon emission intensity of each industry is defined as follows:

$$
e_{i}=\frac{E_{i}}{X_{i}}
$$

Among them, $E_{i}$ is the carbon emission quantity of each department, and $X_{i}$ is the total output of I industry.

Then, according to the total demand coefficient in input and output model to calculate full carbon emission intensity of each industry as follows:

$$
t=e(I-A)^{-1}
$$

Among them, e represents direct carbon emission intensity row vector.

\section{The Calculation Results and Analysis}

\subsection{Direct carbon emissions intensity of each industry in Guangdong province}

According to the calculation process, we may safely draw the direct emissions intensity of industries in Guangdong province, as shown in figure 2: 


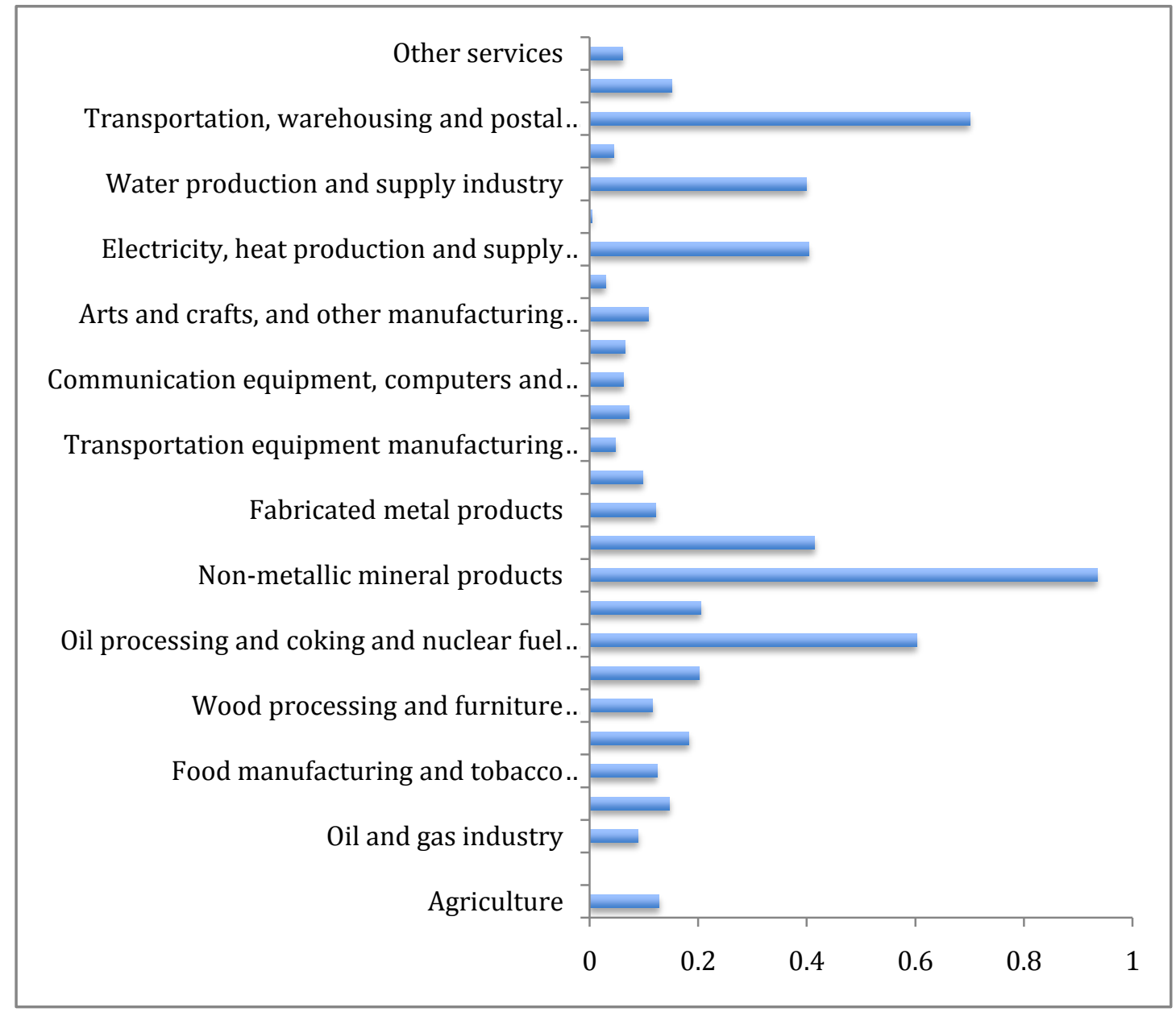

Figure 2 Direct carbon intensity of 27 departments in Guangdong province in 2007 (Unit: tons/ten thousand Yuan)

From above we can see that, industries with direct carbon intensity above 0.5 are as shown in table 2 :

Table 2. Industries with direct carbon intensity above 0.5

\begin{tabular}{|c|c|}
\hline Industry & Directcarbon emission intensity \\
\hline Scrap metal mineral products & 0.935 \\
\hline Transportation, warehousing and postal service & 0.7 \\
\hline Oil processing and coking and nuclear fuel processing industry & 0.602 \\
\hline
\end{tabular}

In addition, we can get the top 10 industries with highest direct carbon intensity in all sectors of the economy, as shown in figure 3:

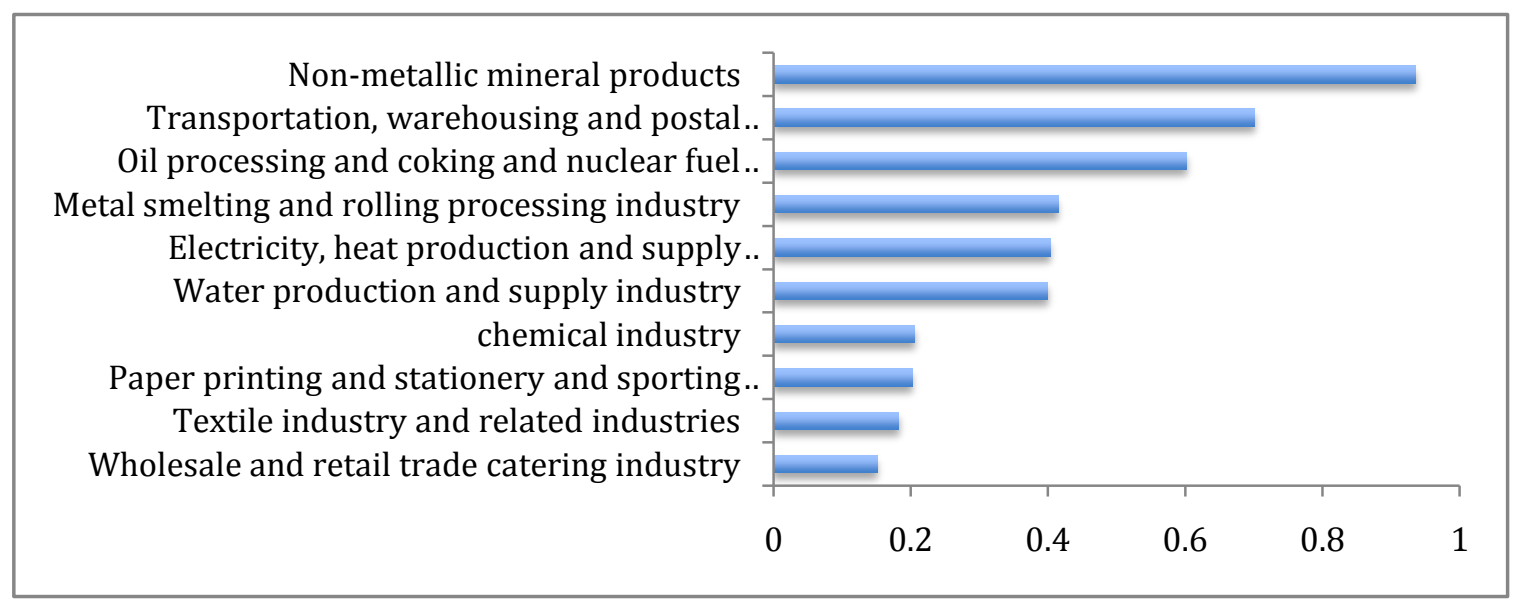

Figure 3. Top 10 industries with highest direct carbon intensity 
From the chart above we can see that, non-metallic mineral products, transportation, warehousing and postal service, oil processing and coking and nuclear fuel processing industry, metal smelting and rolling industry, electric power, heat production and supply industry, water production and supply industry, and chemical industry have comparatively higher carbon emission intensity, in particular, non-metallic mineral products, transportation, warehousing and postal service, oil processing and coking and nuclear fuel processing have a direct carbon emission intensity exceeding 0.5 , among them, the direct carbon emission intensity of nonmetal mineral products is 0.94 , very close to 1 , the highest ranked in the 27 industries. Direct carbon emission intensity reflects direct consumption of energy. It can be seen that in Guangdong province energy and basic industrial industry have higher direct carbon emission intensity.

\subsection{Full carbon emission intensity of all industries in Guangdong Province}

According to the calculation process, we can get full carbon emission intensity for all industries in Guangdong province, as shown in figure 4:

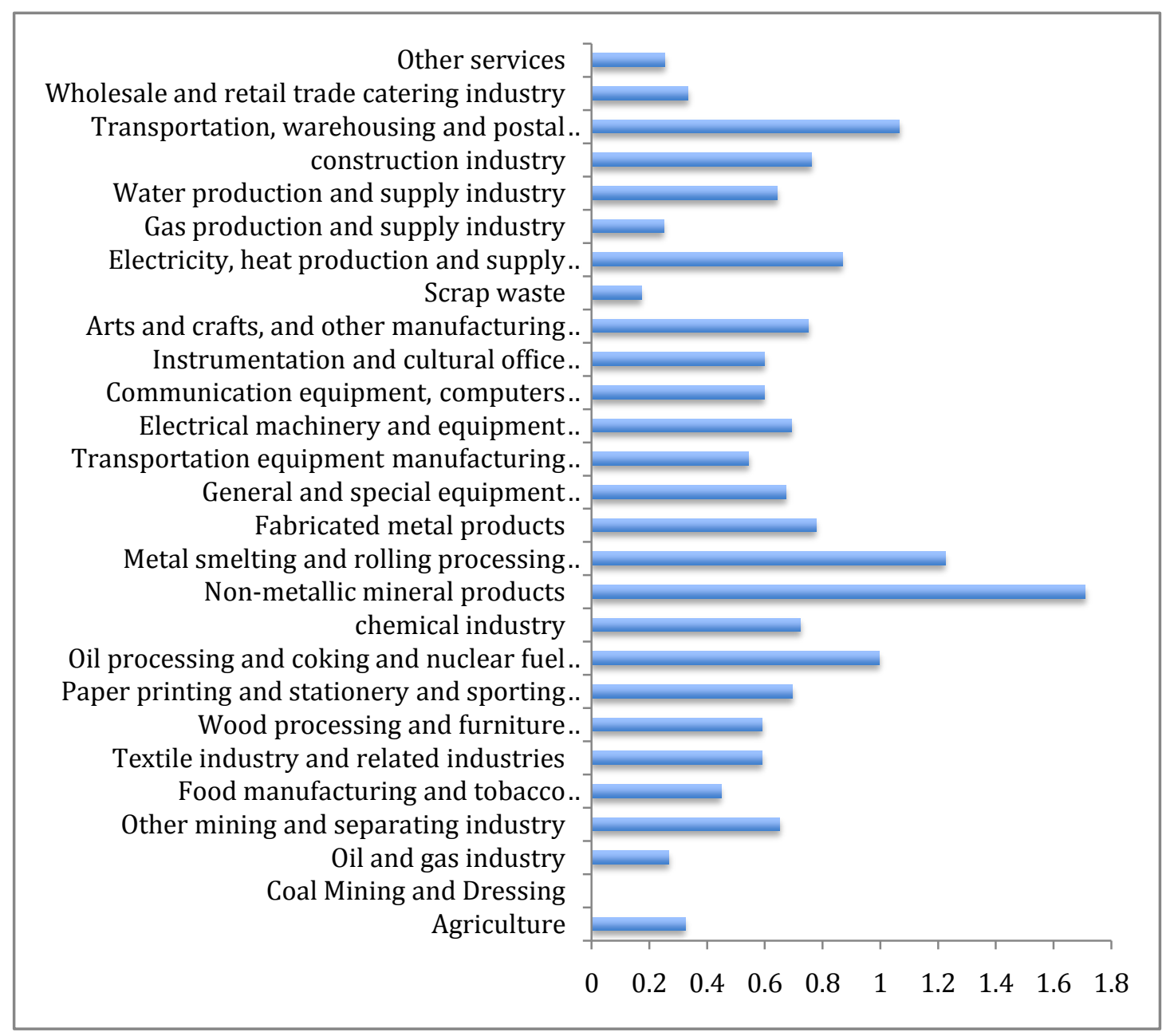

Figure 4. Full carbon emission intensity of all industries in 2007, Guangdong province (unit : Ton/ten thousand Yuan)

We can see, industries with full carbon emission intensity above 0.5 are such as shown in table 3 :

Table 3. Industries with Full carbon emission intensity over 0.5

\begin{tabular}{|c|c|}
\hline Industry & Full carbon emission intensity \\
\hline Other mining and separating industry & 0.6519 \\
\hline Textile industry and related industries & 0.5915 \\
\hline Wood processing and furniture manufacturing & 0.5904 \\
\hline $\begin{array}{c}\text { Paper printing and stationery and sporting goods manufacturing } \\
\text { industry }\end{array}$ & 0.6951 \\
\hline Oil processing and coking and nuclear fuel processing industry & 0.9964 \\
\hline
\end{tabular}


Carbon Emissions Intensity Research in Guangdong Province Based on Input-Output Method

\begin{tabular}{|c|l|}
\hline Chemical industry & 0.7238 \\
\hline Non-metallic mineral products & 1.7097 \\
\hline Metal smelting and rolling processing industry & 1.2246 \\
\hline Metal product industry & 0.7772 \\
\hline General and special equipment manufacturing & 0.6730 \\
\hline Transportation equipment manufacturing industry & 0.5449 \\
\hline Electrical machinery and equipment manufacturing & 0.6926 \\
\hline Communication equipment, computers and other electronic & 0.5978 \\
\hline equipment manufacturing & 0.5998 \\
\hline Instrumentation and cultural office machinery manufacturing & 0.7508 \\
\hline Arts and crafts, and other manufacturing industries & 0.1725 \\
\hline Scrap waste & 0.8689 \\
\hline Electricity, heat production and supply industry & 0.6428 \\
\hline Water production and supply industry & 0.7628 \\
\hline The construction industry & 1.0662 \\
\hline
\end{tabular}

In addition, we can get the top ten highest full carbon intensity Industries in all sectors of the economy, as shown in figure 5:

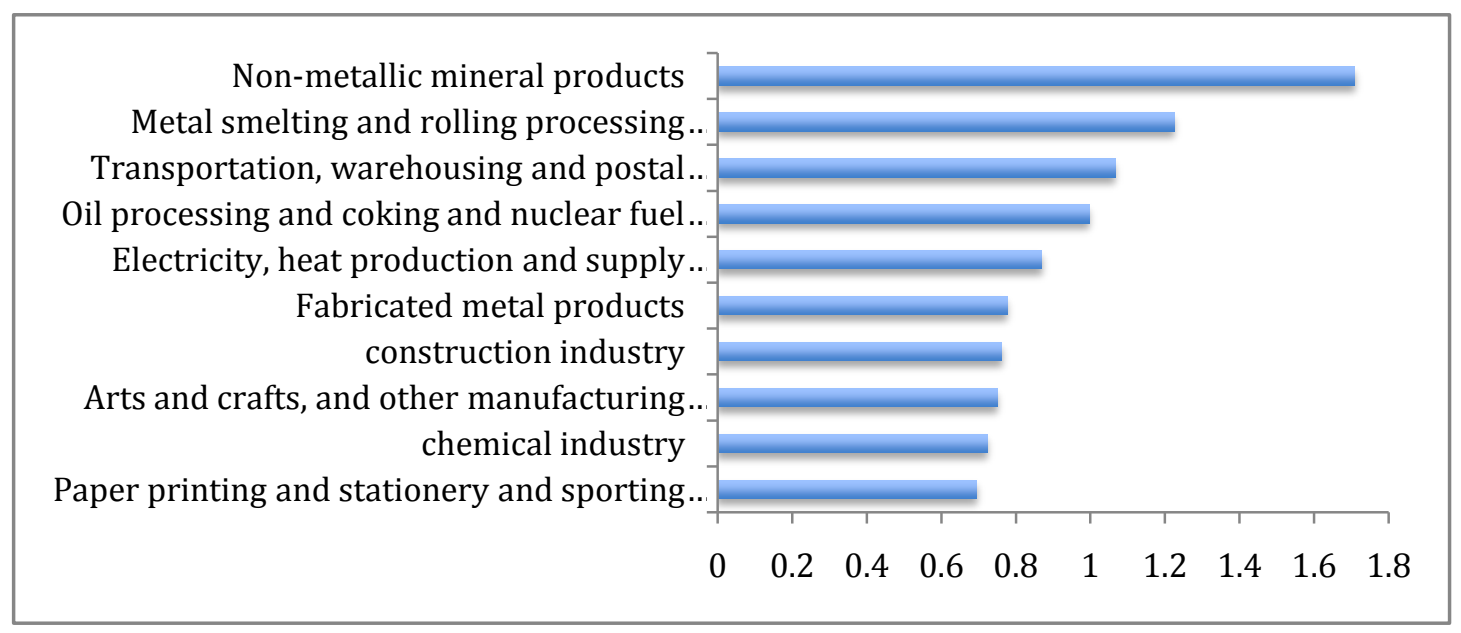

Figure 5. Top Ten Industries with highest full carbon intensity

Full carbon emission intensity uses the industrial connection effect of input and output method, and takes a comprehensive consideration of indirect carbon emissions and direct carbon emissions. We can see from above chart that non-metallic mineral industry, metal smelting and rolling processing industry, transportation, warehousing and postal service, oil processing and coking and nuclear fuel processing industry, electric power, heat production and supply industry, fabricated metal products have higher full carbon emission intensity, among them, full carbon emission intensity of non-metallic products is 1.7 , ranking the top in the 27 industries. Agriculture, oil and gas industry, waste scrap, and gas production and supply industry, other services industries have comparatively lower full carbon emission intensity, among them, full carbon emission intensity of waste scrap is 0.17 , ranking the bottom in the 27 industries.

\subsection{Carbon emission characteristics in Guangdong province}

From the above results, we can see that the ranking of full carbon emission intensity is not completely consistent with direct carbon emission intensity. To analyze the carbon emission characteristics of different industries, a comparison between full carbon emission intensity and direct carbon emission intensity of all industries in Guangdong province in 2007 was executed. In analyzing carbon emission efficiency, we should consider both direct carbon emissions and indirect emissions, so as to truly reflect the carbon emission conditions in various industries, and take different measures for different types of industry.

Therefore, in order to further analyze carbon emission characteristics of different industrial sectors, 
we take 0.5 as the boundary, and divide the direct carbon emission intensity and full carbon emission intensity into four regions, which further classify the 27 industries into different groups, to observe the distribution of the industrial sectors and their carbon emission characteristics as shown in table 4:

Table 4. Division of 27 industries according to carbon emission intensity

\begin{tabular}{|c|c|c|}
\hline & Direct carbon emission intensity lower than 0.5 & $\begin{array}{l}\text { Direct carbon emission intensity higher } \\
\text { than } 0.5\end{array}$ \\
\hline \multirow{7}{*}{$\begin{array}{l}\text { Full carbon } \\
\text { emission } \\
\text { intensity } \\
\text { lower than } \\
0.5\end{array}$} & Agriculture & \\
\hline & Oil and gas industry & \\
\hline & $\begin{array}{l}\text { Food manufacturing and tobacco processing } \\
\text { industry }\end{array}$ & \\
\hline & Scrap waste & \\
\hline & Gas production and supply industry & \\
\hline & Wholesale and retail trade catering industry & \\
\hline & Other services industry & \\
\hline \multirow{16}{*}{$\begin{array}{l}\text { Full carbon } \\
\text { emission } \\
\text { intensity } \\
\text { higher than } \\
0.5\end{array}$} & Other mining and separating industry & \multirow{6}{*}{$\begin{array}{l}\text { Oil processing and coking and nuclear } \\
\text { fuel processing industry }\end{array}$} \\
\hline & Textile or related industry & \\
\hline & Wood processing and furniture manufacturing & \\
\hline & $\begin{array}{l}\text { Paper printing and stationery and sporting goods } \\
\text { manufacturing industry }\end{array}$ & \\
\hline & The chemical industry & \\
\hline & Metal smelting and rolling processing industry & \\
\hline & Fabricated metal products & \multirow{5}{*}{ Non-metallic mineral products industry } \\
\hline & General and special equipment manufacturing & \\
\hline & Transportation equipment manufacturing industry & \\
\hline & Electrical machinery and equipment manufacturing & \\
\hline & $\begin{array}{c}\text { Communication equipment, computer } \\
\text { manufacturing with other electronic equipment }\end{array}$ & \\
\hline & $\begin{array}{c}\text { Instrumentation and cultural office machinery } \\
\text { manufacturing }\end{array}$ & \multirow{5}{*}{$\begin{array}{c}\text { Transportation, warehousing and postal } \\
\text { service industry }\end{array}$} \\
\hline & Arts and crafts, and other manufacturing industries & \\
\hline & Electricity, heat production and supply industry & \\
\hline & Water production and supply industry & \\
\hline & The construction industry & \\
\hline
\end{tabular}

Hence, we could divide the industries into three parts :

The first class industry is low carbon emission industry with low direct carbon emission intensity and full carbon emission intensity. Direct carbon emission intensity and full carbon emission intensity are less than 0.5 tons/ten thousand Yuan both. This class industry is mainly the agriculture industry; food production and tobacco processing scrap waste and service industry. Service is mainly provided by human labor, energy consumption is only auxiliary condition for production or service activity, therefore its direct carbon intensity and full carbon emission intensity is very low. Agricultural input in the production process mainly includes agricultural production products and labor input. Because agricultural production products are always with low energy consumption, and agriculture is in low degree modernization, it is always with low direct carbon intensity and full carbon emission intensity. Food production and tobacco processing industry, textile and related industry belongs to laborintensive industry, with low direct carbon emission intensity. The intermediate inputs of these industries are mainly agricultural products and light industry materials with low energy consumption, so the indirect carbon emission intensity of these industries is not high either.

The second industry is complied high carbon emission industry with low direct carbon emission intensity, while high full carbon emission intensity. These industries have direct carbon emission intensity less than 0.5 tons/ten thousand Yuan, and full carbon emission intensity higher than 0.5 tons/ten thousand Yuan. In these 27 industries, a total of 17 industries belong to the implied high carbon emission industry, including other mining and separating industry, wood and textile, chemical refining, all sorts of equipment manufacturing, supply of electricity, heat production and water, and construction industry. Because the intermediate inputs for this kind of industry are products from 
high-energy consumption industries such as steel, cement, metal products, which always cause very high indirect carbon emissions.

The third industry is high carbon emission industry with high direct carbon emission intensity, and high full carbon emission intensity. The direct carbon emission intensity of this kind industry is higher than 0.5 tons/ten thousand Yuan, while full carbon emission intensity is lower than 0.5 tons/ten thousand Yuan. Mainly including the oil processing and coking and nuclear fuel processing industry, non-metal mineral products industry, and transportation, storage and postal service industry. These industries are basically high-energy consumption industry from traditional sense, requiring directly heavy use of energy.

\section{Policy Suggestions}

According to the direct carbon emission intensity and full carbon emission intensity, we divide the 27 industries in Guangdong province into three types, with different carbon emission characteristics. According to the characters of their carbon emission, we can put forward different mitigation measures.

\subsection{In view of high energy-consuming and carbon emission industry}

From the above analysis results, we can see that high carbon emission industry is basically the traditional high energy consumption industry, hence reduce energy consumption of such industries, has certain practical significance in controlling the source of the whole national economic system.

First of all, constantly enhance the capacity of independent innovation relying on scientific and technological progress; effectively develop the special function of advanced technology in energy saving of high energy consumption and high carbon emission industry; increase development of energy-saving technologies. Secondly, design the plan and policy of developing high energyconsuming industry; increase the access threshold of energy conservation and environmental protection market; strictly control the construction of energy consuming, and high pollution projects, and effectively control the excessively rapid growth of high energy-consuming industry and polluting industries. Encourage use of high and new technology and advanced applicable technical transformation to upgrade traditional industries, to promote optimization and upgrade of traditional industry structure. Lastly, fix product energy efficiency standards, and seize energy saving of key products.

\subsection{In view of the implied high carbon emission industry}

From the above analysis results, we can see that since the intermediate input of implied high carbon emission industries are energy-intensive products such as steel, cement, metal products, which always bring high indirect carbon emission. So the reduction of implied carbon emission in construction and other similar industries is mainly to reduce intermediate inputs or increase replacement for highenergy consumption inputs.

To achieve this goal, constant technological innovation should be conducted. The first is to optimize production plan on basis of the traditional mainstream technology, to improve the efficiency of resource utilization through the optimization of product design and process design, or to replace highenergy inputswith low energy inputs. The second is to carry out technique improvement of equipment, to improve the material utilization in existing equipment. The Third is executing technical innovation and invention, by implementing the material recycling and resource recycling, the material use, to optimize energy use and ecological efficiency, thus to realize multilevel recycling of resources

\subsection{In view of the low carbon industry}

From the analysis we can see that the low-carbon emission industries are mainly service industry, so development of service industry should be grasped as a breakthrough to conduct energy conservation and emission reduction work. Raise the proportion of service industry in GDP, especially develop low energy consumption and high added value modern service industries, like financial insurance, tourism, consulting, intermediary services, information services, and modern logistics industry, etc., thus to control excessive demand for energy consumption. While in vigorous development of modern service industry, we should also standardize promote traditional service industry, which is beneficial 
to industrial structure to develop to-warding the direction of low energy consumption, and low carbon emission.

\section{REFERENCES}

G Ipek Tunc, Serap Turut-Aslk, Elif Akbostanci Emissions vs Responsibility: An Input-output Approach for the Turkish Economy[ J ]. Energy Policy, 2007( 35) :855-868

Machado G, Schaeffer R, Worrell E. Energy and Carbon Embodied in the International Trade of Brazil: An Input-output Approach[ J ]. Ecological Economics, 2001(39): 409-424

Wiedmann T. A First Empirical Comparison of Energy Footprints Embodied in Trade-MRIO versus PLUM [J]. Ecological Economics, 2009(7):1975 - 1990.

Zhi-hui zhang. Carbon emissions accounting in Constructio Industry based on the input and output analysis [J]. Journal of tsinghua university, 2013, 53(1): 53-57

Yuan Yujie, Jiang yu-mei. Tourism carbon emission accounting based on input-output analysis [J]. Journal of Central South University of Forestry and Technology, 2013, 7(3): 1-6

Qin Changcai, Liu shu-lin. Full carbon emission study on Chinese industry based on input-output analysis[J]. Journal of statistics and information BBS 2013, 28(9): 32-38

Wei Benyong, fang Xiuji, Wang Yuan, Yang Huimin, Zhang Di. Research on implied carbon emission in China's international trade based on input-output analysis[J]. Journal of Beijing Normal University 2009, 45(4): 413-419

Zhang Duanduan. Research on implied carbon emission in China's textile trade based on input-output analysis [D]. Shanghai: Donghua University, 2014.

Sun Jianwei, Chen zhigang, Zhao Rongqin, Huang Xianjin, Lai Li. Footprint research of china's carbon emission based on the input-output analysis[J]. China population resources and environment, 2010, 20(5): 28-34

Ye Zhen. Input and output data update method and its application in carbon emission analysis [J]. Journal of statistics and information BBS, 2012, 27(9): 39-44

Zhu Qin, Peng xizhe, Wu kaiya. Calculation and Analysis on Indirect Carbon Emissions from Residential Consumption Based on Input-Output Model[J]. Journal of natural resources, 2012, 27(12): 2018-2029

Chen Lin. Analysis on the influence factors of carbon emissions change from China's energy consumption [J]. Chinese and foreign sources of energy, 2013, 18(1): 17-22

Zhuang, Zongming,Wei Duan. China's carbon emissions change trend and its influencing factors [J]. Journal of xiamen university, 2014, (5): 107-116

Citation: YU Chen et al., " Carbon Emissions Intensity Research in Guangdong Province Based on InputOutput Method ", International Journal of Research in Environmental Science, vol. 4, no. 1, p. 27-38, 2018. http://dx.doi.org/ 10.20431/2454-9444.0401004

Copyright: (0) 2018 Authors. This is an open-access article distributed under the terms of the Creative Commons Attribution License, which permits unrestricted use, distribution, and reproduction in any medium, provided the original author and source are credited. 